\title{
Simulation on Sequential Construction Process and Structure of the Pisa Tower
}

\author{
Jun Geng ${ }^{1^{*}}$, Zuping Meng2* ${ }^{*}$ Bangxun Yin ${ }^{3 *}$, Liufei Zhu ${ }^{4^{*}}$ \\ ${ }^{1}$ Jilin University, Jilin, China \\ ${ }^{2}$ National Chiao Tung University, Taiwan, China \\ ${ }^{3}$ University of Manchester, Manchester, UK \\ ${ }^{4}$ The Experimental High School Attached to Beijing Normal University, Beijing, China \\ Email: blairgeng@outlook.com
}

How to cite this paper: Geng, J., Meng, Z.P., Yin, B.X. and Zhu, L.F. (2020) Simulation on Sequential Construction Process and Structure of the Pisa Tower. Journal of Building Construction and Planning Research, 8, 30-41.

https://doi.org/10.4236/jbcprt.2020.81003

Received: September 17, 2019

Accepted: January 17, 2020

Published: January 20, 2020

Copyright $\odot 2020$ by author(s) and Scientific Research Publishing Inc. This work is licensed under the Creative Commons Attribution-NonCommercial International License (CC BY-NC 4.0). http://creativecommons.org/licenses/by-nc/4.0/

\begin{abstract}
The leaning of structures happens all around the world and generates impacts on different extents; thus, it is important to learn about the causes behind. In this report, the sequential construction of a typical leaning structure, the Tower of Pisa, is discussed and simulated by using a finite element code, PLAXIS. The simulation is performed on a two-dimensional plane with simplifications taken into consideration in making modeling feasible under limitations. Three distinct models are built with one as a control variable, while the other two models are set up with exact eccentricity. Data are obtained from the analysis and are plotted in a graph to clearly show the relationship between the tilting angle and construction phases. With reasonable and completed simulation, the study is able to show the significant role compressible subsoil plays in impacting the tilting performance of a tall building.
\end{abstract}

\section{Keywords}

The Leaning Tower of Pisa, Tilting Angle, Sequential Construction, Subsoil, Tilting Performance, PLAXIS

\section{Introduction}

The leaning tower of Pisa is one of the most remarkable architectural structures in medieval Europe. Constructed in 1173, the tower is round and is constructed throughout of white marble, inlaid on the exterior with colored marbles. The uneven settling of the campanile's foundations during its construction gave the structure a marked inclination that is now about 17 feet $(5.2 \mathrm{~m})$ out of the per-

*These are co-first authors, sorted by alphabetical order of last name. 
pendicular [1]

Currently, the tower is approximately 60 meters tall; the highest side is 56.67 $\mathrm{m}$, and the lowest side is $55.86 \mathrm{~m}$. And the outer diameter is $15.484 \mathrm{~m}$. The overall form of the tower is a hollow cylinder subdivided into eight orders, with spiral staircase leading to the top. Colonnade is engraved on the wall of the base floor; the middle six stories are surrounded by marble columns and loggias; a belfry, which is always denoted as the Bell Chamber, is constructed at the top. The significant events in the construction history of the leaning tower of Pisa were shown in Table 1.

Began in 1173, the tower's construction process was interrupted after 5 years when three and one third floors were completed, and the tower was leaning to the north about 0.25 degrees. The tower continued to move towards a more upright position when the work finished [2].

However, when the $7^{\text {th }}$ floor was finished in 1278 , the tower tilted back to south by about 0.6 degrees and increased to 1.6 degrees in about 90 years. In 1817 , the first measurement of the tilting angle was recorded, showing that the angle is about 5 degrees toward the south. After centuries of repairs and adjustments, the inclination decreased approximately to about 4 degrees. As Pisans say, the tower is "banana-shaped", with the bell tower 1.5 degrees closer to the vertical than the base [3]. The inclining angle of the tower over time could be seen from Figure 1.

The objective of this research is to simulate the sequential construction of the leaning tower of Pisa. One of the important reasons is that the tower of Pisa is currently the world's most ancient and famous leaning structure which means that there are more historical recordings and articles published about this leaning tower. Those can give us more freedom in choosing data for simulation and the tilting of the Tower of Pisa itself is also a very representative architectural problem.

To this end, the finite element software PLAXIS 8.2 [5] is utilized to capture the process of staged construction. This is because PLAXIS has the functions to simulate the consolidation problems and step construction. Those functions are required for this simulation to be achieved. Even though the version of the code restraint the study to two-dimensional plane strain modeling, and the premises

Table 1. Significant events in the construction history.

\begin{tabular}{cl}
\hline Period & \multicolumn{1}{c}{ Events } \\
\hline $1173-1178$ & More than 3 floors of the tower had built when it started leaning \\
$1178-1272$ & Construction of tower was interrupted and consolidation of the soil took place \\
$1272-1278$ & Stage construction to $7^{\text {th }}$ floor was completed \\
$1278-1360$ & Consolidation of the soil took place \\
$1360-1370$ & Construction of bell chamber took place \\
1859 & The inclination angle of the tower was measured to be about 5.5 degrees
\end{tabular}




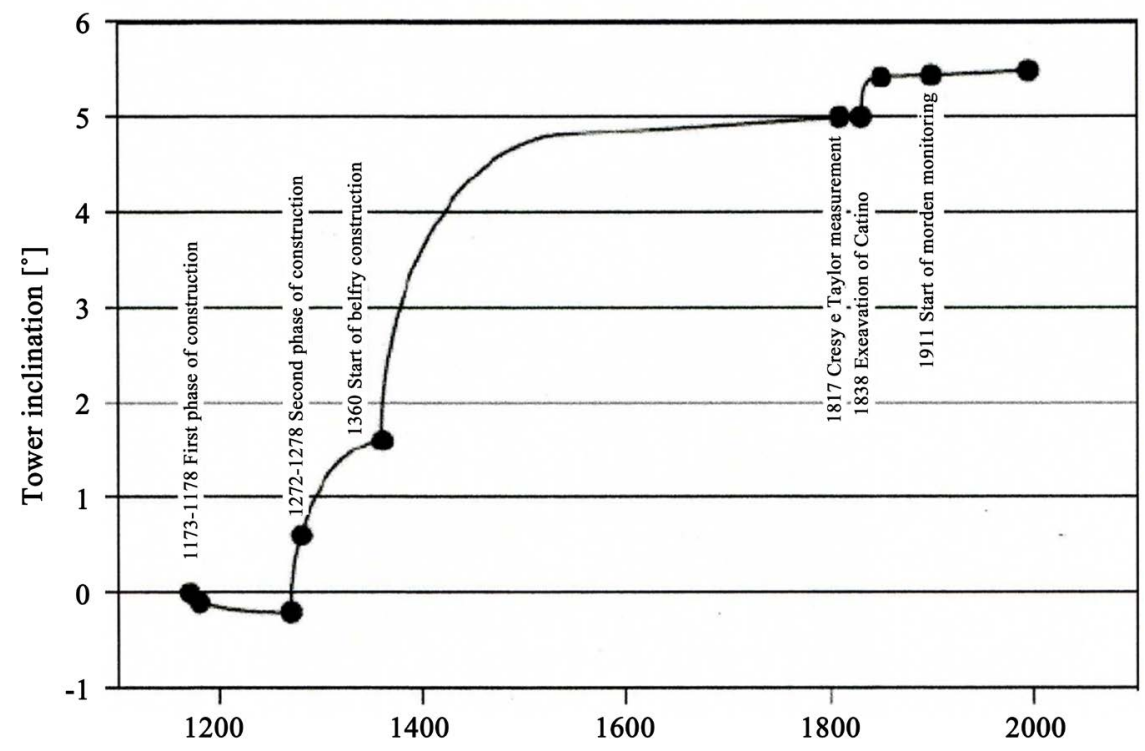

Figure 1. The inclining angle over time [4].

do not accurately reflect the geometrical features of the Pisa tower, the proposed study is useful in gaining insight into how subsoil foundations impact the performance of a tall structure. The study also provides an opportunity to utilize an advanced finite element code in modeling complex boundary-value problems, such as those arising from the sequential construction of a world heritage.

Soil Structure Interaction (SSI) is the process of mutual interaction between soil and structure, that is, under external forces, the response of the soil influences the motion of the structure and vice versa. Conventional structural design methods usually neglect the SSI effects, which is feasible under light structures in relatively stiff soil, but the effects become prominent when heavy building is resting on soft soils; the leaning tower of Pisa, which is mostly comprised of heavy stones and was built on compressible soil, can be a typical example of the latter situation. Therefore, this research is a simple exploration into the soil structure interaction between the leaning tower of Pisa and the soil beneath.

\section{Subsoil Condition}

The tower of Pisa was built on highly compressible soils and started leaning at the very beginning. The ground profile beneath the tower consists of three separate layers as shown in Figure 2. Horizon A is about $10 \mathrm{~m}$ thick, consisting of a 2-meter-thick fine sand layer, the upper sand, which has medium density. Horizon B is at a greater depth of about $40 \mathrm{~m}$, primarily consisting of marine clay. This layer is subdivided into four distinct layers. The uppermost layer is soft sensitive clay, locally known as the Pancone clay; the second layer consists of stiffer clay, and the third layer beneath is intermediate sand; a consolidated clay, known as the lower clay, is at the bottom. Horizon B is especially laterally uniform under the tower. Horizon $\mathrm{C}$ is a dense sand layer extending to a depth more than 60 meters; it primarily comprises the lower sands. The average 


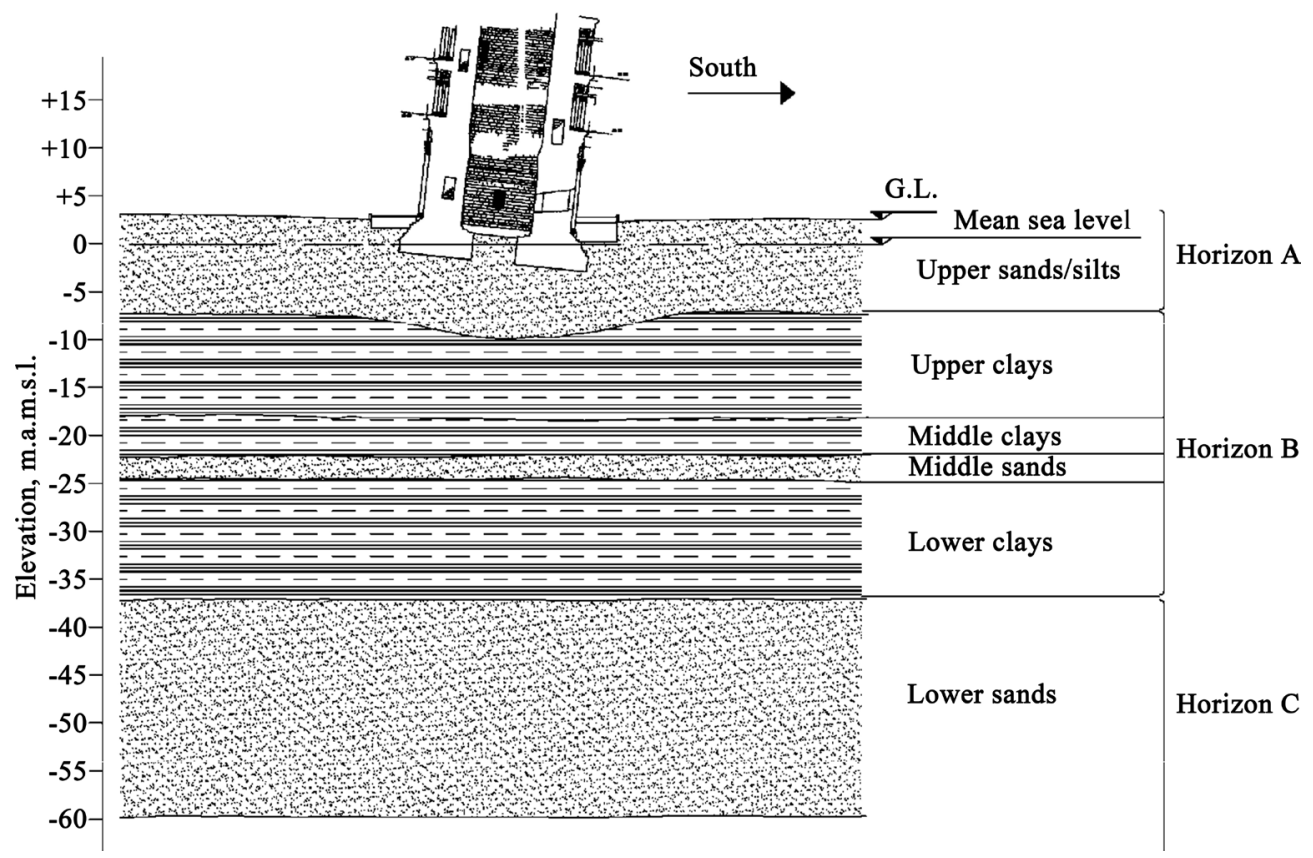

Figure 2. The subsoil of the Tower [7].

ground water elevation is 3 meters above the mean sea level, while aquifers in Horizon A, located at a depth between $1 \mathrm{~m}$ and $2 \mathrm{~m}$, create challenging problems on protecting the tower. This information is quite essential since the depth of soil layer strongly affects the structural response [6].

\section{Assumptions on the Tilting Structure}

Based on the aforementioned background of the tilting structure, following assumptions can be made. The first one is that the mass and weight of the building are uniformly distributed. Then the building is rectangular in shape and the building's deformation is small compared to its rigid-body motion. There is no relative movement between the soil and the building at their interface. The material of the building is elastic and the building is tilting in the plane defined along width and height; therefore, it will be a two-dimension simulation. Finally, the ground elevation is $0 \mathrm{~m}$.

\section{Numerical Model}

Some simplifications of the problem are conducted to make the simulation feasible under limitations. The structure was concerned to be an 8-storied perfectly vertical building in height of $60 \mathrm{~m}$, in length of $100 \mathrm{~m}$, in width of $19 \mathrm{~m}$, with 5 $\mathrm{m}$ embedded underground as shown in Figure 3.

When simulating, the building was assumed to tilt in a certain direction. Additional information is shown in Table 2.

The subsoil profile was assumed to consist of four layers in Mohr-Coulomb model to simulate their constitutive behavior. The profile is given in Table 3 and Table 4. 


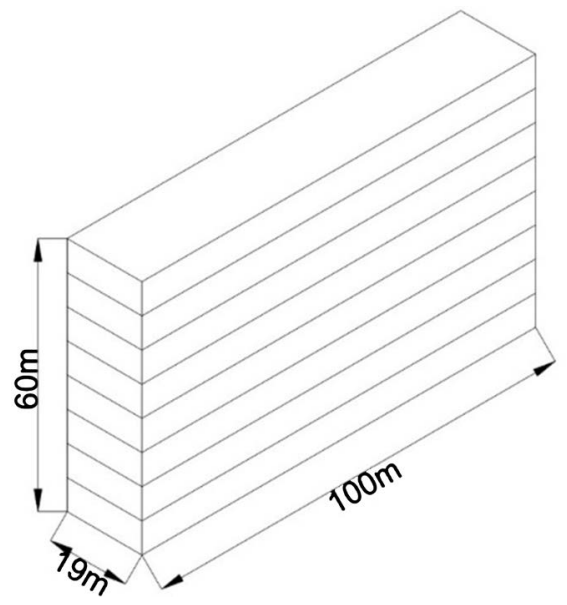

Figure 3. The building model.

Table 2. Building information.

\begin{tabular}{ccc}
\hline Number of stories & Story height $(\mathrm{m})$ & Individual story weight $(\mathrm{MN})$ \\
\hline 1 & 11.8 & 826.15 \\
2 & 6.94 & 496.35 \\
3 & 6.94 & 464.60 \\
4 & 6.59 & 421.15 \\
5 & 6.24 & 385.20 \\
6 & 6.24 & 375.95 \\
7 & 6.94 & 412.60 \\
8 & 8.32 & 492.50
\end{tabular}

Table 3. Soil information on the side of lower foundation stress.

\begin{tabular}{|c|c|c|c|c|c|c|c|c|}
\hline Layers & $\begin{array}{l}\text { Unit weight } \\
\left(\mathrm{kN} / \mathrm{m}^{3}\right)\end{array}$ & $\begin{array}{l}\text { Saturated unit } \\
\text { weight }\left(\mathrm{kN} / \mathrm{m}^{3}\right)\end{array}$ & $\begin{array}{l}\text { Elastic modulus } \\
\qquad\left(\mathrm{kN} / \mathrm{m}^{2}\right)\end{array}$ & $\begin{array}{l}\text { Poisson's } \\
\text { ratio }\end{array}$ & $\begin{array}{c}\text { Cohesion } \\
\left(\mathrm{kN} / \mathrm{m}^{2}\right)\end{array}$ & $\begin{array}{l}\text { Friction } \\
\text { angle }\left({ }^{\circ}\right)\end{array}$ & $\begin{array}{l}\text { Dilatancy } \\
\text { angle }\left(^{\circ}\right)\end{array}$ & $\begin{array}{c}\text { Permeability } \\
\text { (m/day) }\end{array}$ \\
\hline $\operatorname{artificial~fill~}(0 \sim-7 \mathrm{~m})$ & 15 & 18 & 15,000 & 0.2 & 3 & 35 & 0 & 1 \\
\hline fine sand $(-7 \sim-20 \mathrm{~m})$ & 17 & 20 & 20,000 & 0.2 & 4 & 30 & 0 & 1 \\
\hline sand $(-20 \sim-30 \mathrm{~m})$ & 16 & 18 & 18,000 & 0.25 & 2 & 30 & 0 & 1 \\
\hline clay $(-30 \sim-40 \mathrm{~m})$ & 14 & 17 & 4000 & 0.15 & 15 & 20 & 0 & 0.001 \\
\hline
\end{tabular}

Table 4. Soil information on the side of higher foundation stress.

\begin{tabular}{|c|c|c|c|c|c|c|c|c|}
\hline Layers & $\begin{array}{l}\text { Unit weight } \\
\left(\mathrm{kN} / \mathrm{m}^{3}\right)\end{array}$ & $\begin{array}{c}\text { Saturated unit } \\
\text { weight }\left(\mathrm{kN} / \mathrm{m}^{3}\right)\end{array}$ & $\begin{array}{l}\text { Elastic modulus } \\
\qquad\left(\mathrm{kN} / \mathrm{m}^{2}\right)\end{array}$ & $\begin{array}{l}\text { Poisson's } \\
\text { ratio }\end{array}$ & $\begin{array}{c}\text { Cohesion } \\
\left(\mathrm{kN} / \mathrm{m}^{2}\right)\end{array}$ & $\begin{array}{l}\text { Friction } \\
\text { angle }\left({ }^{\circ}\right)\end{array}$ & $\begin{array}{l}\text { Dilatancy } \\
\text { angle }\left({ }^{\circ}\right)\end{array}$ & $\begin{array}{c}\text { Permeability } \\
\text { (m/day) }\end{array}$ \\
\hline $\operatorname{artificial~fill~}(0 \sim-10 \mathrm{~m})$ & 15 & 18 & 15,000 & 0.2 & 3 & 35 & 0 & 1 \\
\hline fine sand $(-10 \sim-15 \mathrm{~m})$ & 17 & 20 & 20,000 & 0.2 & 4 & 30 & 0 & 1 \\
\hline sand $(-15 \sim-30 \mathrm{~m})$ & 16 & 18 & 18,000 & 0.25 & 2 & 30 & 0 & 1 \\
\hline clay $(-30 \sim-40 \mathrm{~m})$ & 14 & 17 & 4000 & 0.15 & 15 & 20 & 0 & 0.001 \\
\hline
\end{tabular}




\section{Finite Element Model}

In order to simplify the loading condition, the weight of each floor is taken as concentrated load at the centroid as shown in Figure 4, which has the same effect as distributed load.

The initial simulation model (model 1 ) is a vertical ghost building with vertical point loads on the centroid of each floor as shown in Figure 5. The structure of sand layers will cause uneven sinking and make the building tilt without other setting. However, the $2 \mathrm{D}$ model in PLAXIS is unable to simulate non-linear conditions so that an angle of tilt in the initial setting is required to generate an eccentricity which can make simulation closer to realistic condition.

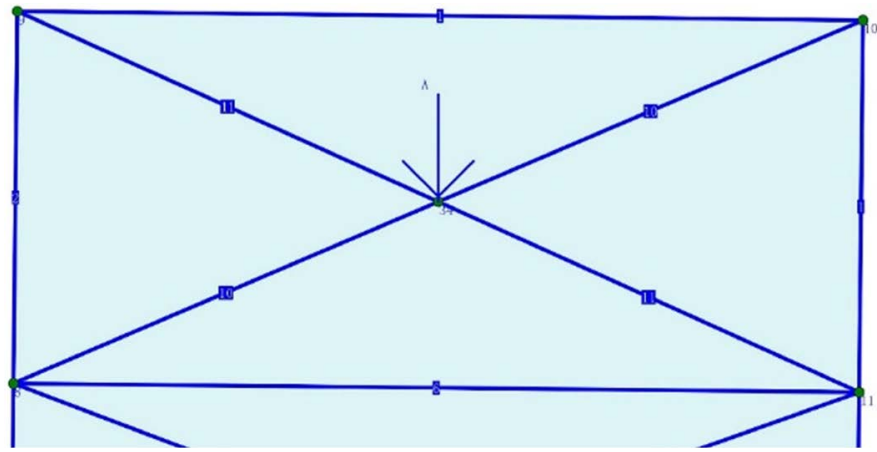

Figure 4. The loading condition.

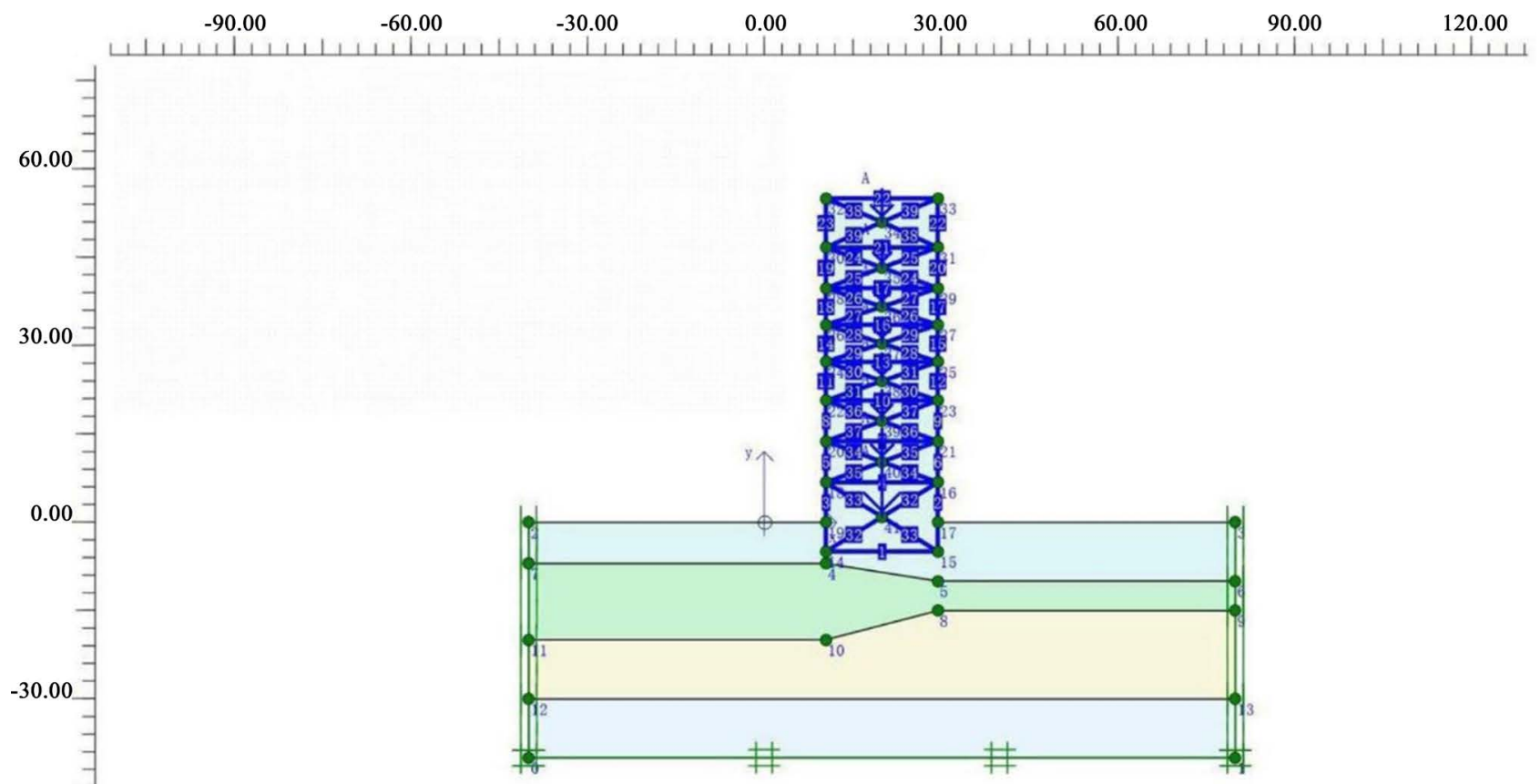

$-60.00$

Figure 5. Geometry model (model 1). 
In order to locate the load with exact eccentricity, it is assumed that the entire building starts to tilt at 0.6 degrees as the construction begins. The geometry model (model 2) could be built in 2D as shown in Figure 6.

The building could be defined as crossing plates with high stiffness with deformation ignored. The weight of each plate is included in the overall weight of the floor; therefore, the input magnitude each member weighs should be zero. Table 5 shows the properties of each member.

The finite elements are produced by meshing the entire geometry with medium element distribution and refining the cluster around the box foundation for more precise calculation. The meshing result is shown in Figure 7.

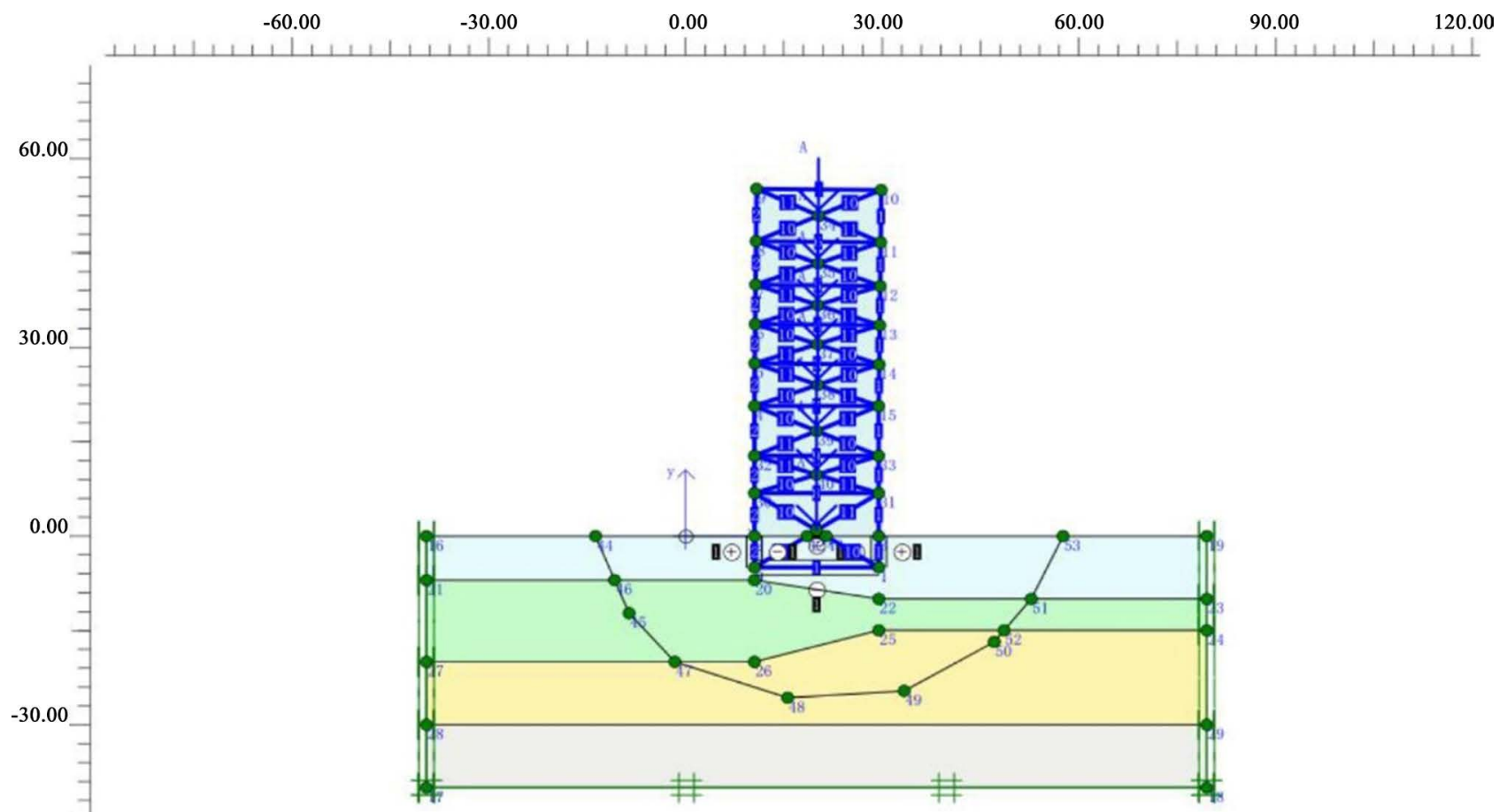

$-60.00$

Figure 6. Geometry model (model 2).

Table 5. Material properties of the members.

\begin{tabular}{cccc}
\hline Parameter & Name & Value & Unit \\
\hline Type of behavior & $E A$ & Elastic & \\
Normal stiffness & $E I$ & $1 \times 10^{10}$ & $\mathrm{kN} / \mathrm{m}$ \\
Flexural rigidity & $d$ & $1 \times 10^{10}$ & $\mathrm{kN} \cdot \mathrm{m}^{2} / \mathrm{m}$ \\
Equivalent thickness & $w$ & 3.464 & $\mathrm{~m}$ \\
Weight & $v$ & 0 & $\mathrm{kN} / \mathrm{m} / \mathrm{m}$ \\
Poisson's ratio & & 0.3 & \\
\hline
\end{tabular}




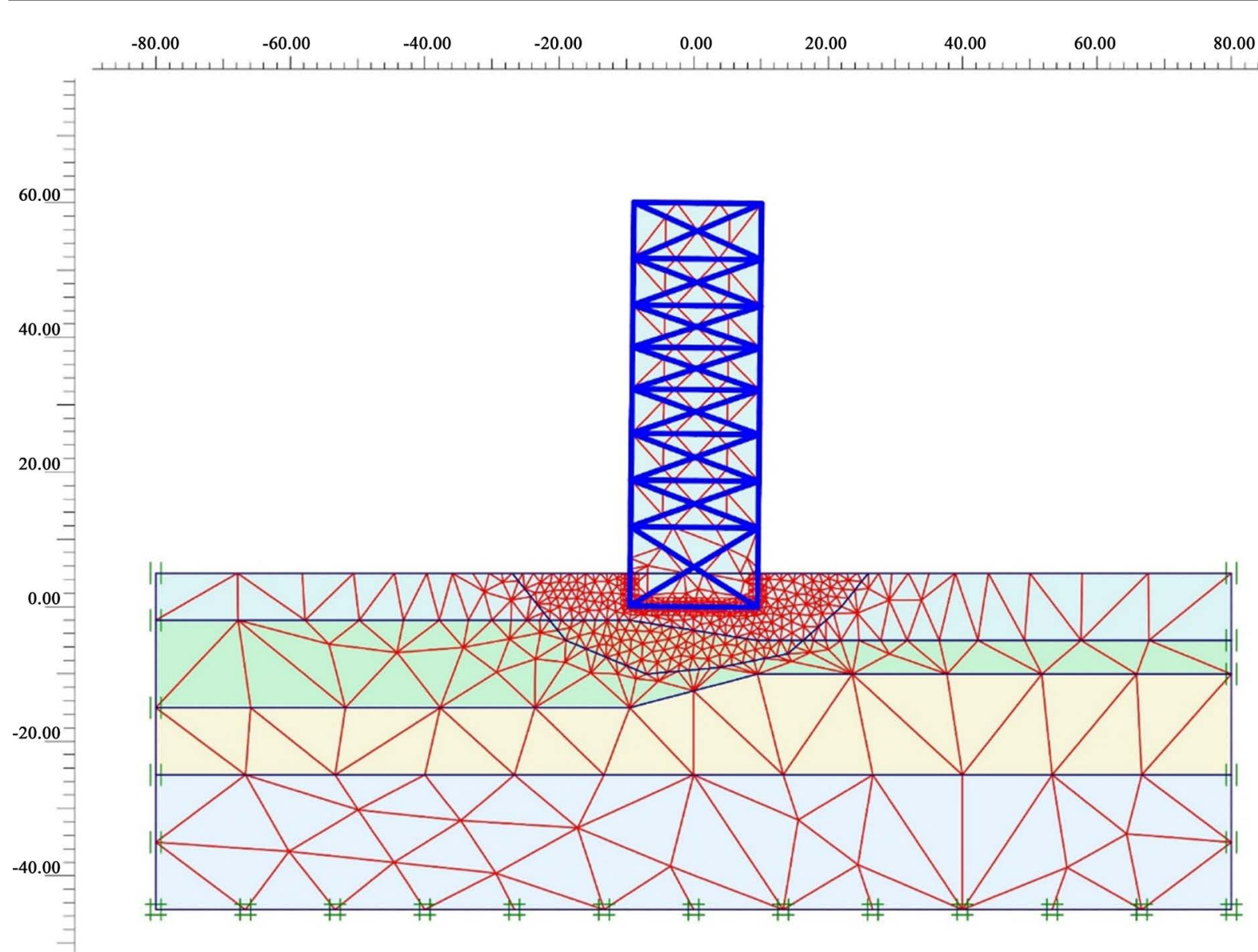

Figure 7. Meshing result (model 2).

In order to simulate the tilt during tower's construction, the lower three floors should be revised to be perpendicular to the ground, because uneven sinking is so small that the tilt could be ignored. The upper five floors should be revised to tilt at 0.6 degrees because of the uneven sinking caused by soil consolidation. Therefore, the geometry model (model 3) could be built in 2D as shown in Figure 8.

Material properties of the members and the meshing process are the same with the previous model. The meshing result is shown in Figure 9.

\section{Simulation Results}

The equivalent point load could be defined by:

$$
\bar{p}=\frac{\text { Weight }}{\text { Length }}
$$

Therefore, the simulation results could be obtained from PLAXIS as shown in Table 6 and Figure 10.

\section{Advantages and Weaknesses}

There are several advantages about the current modeling process. The numerical model can be set up with ease, since the shape of the horizontal section of the 


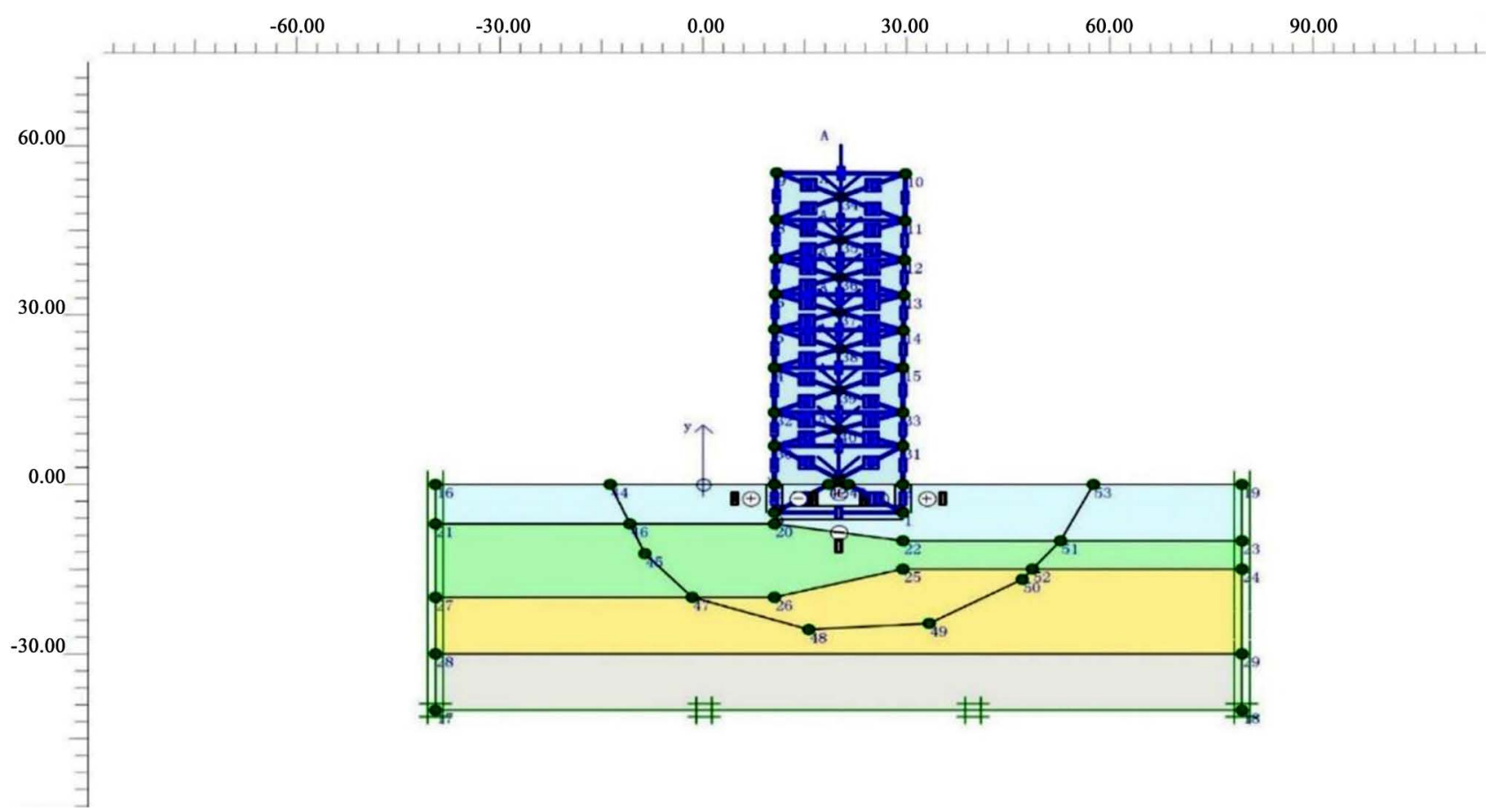

Figure 8. Revised geometry model (model 3).

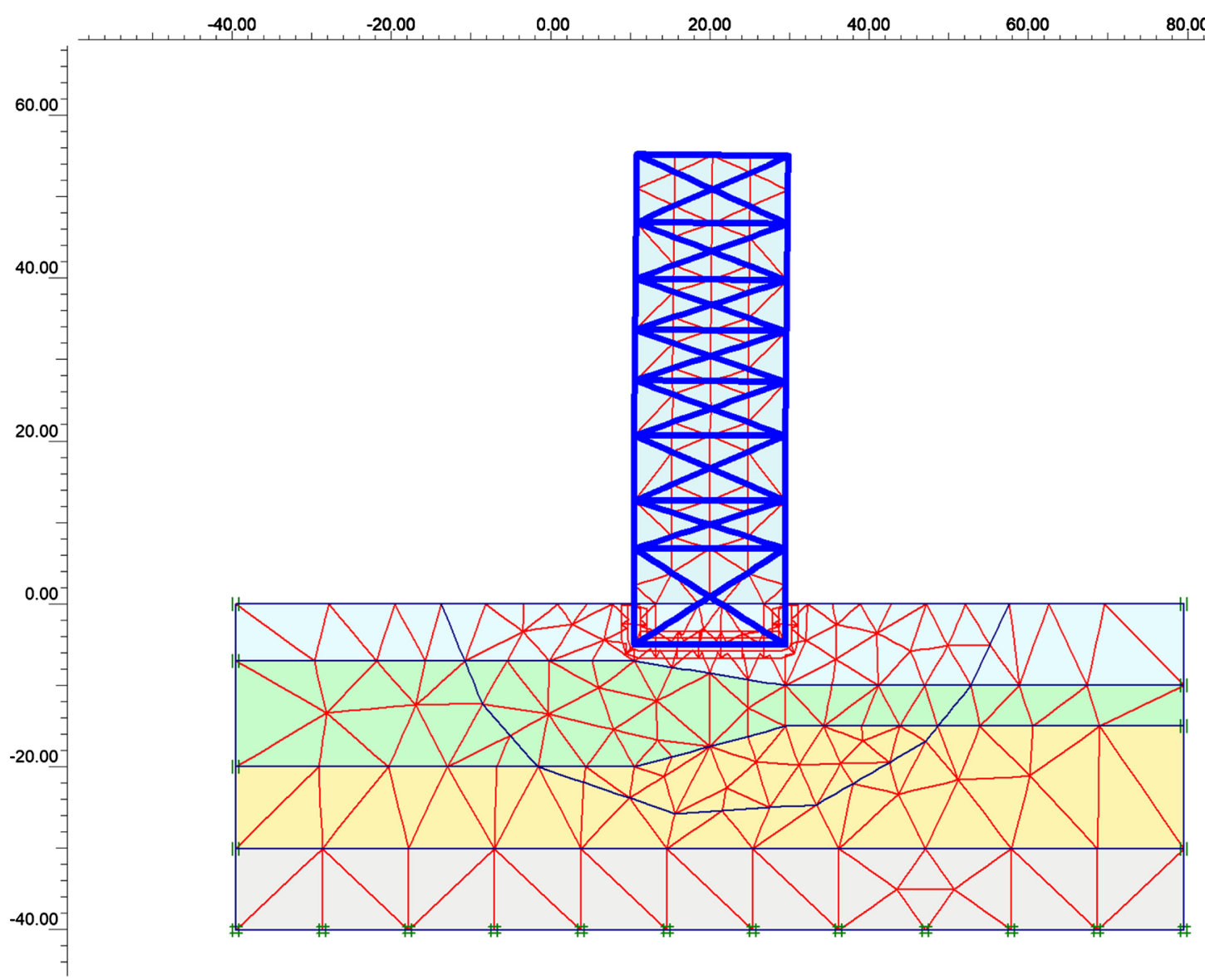

Figure 9. Meshing result (model 3). 
Table 6. Simulation results.

\begin{tabular}{cccccc}
\hline Floors & $\begin{array}{c}\text { Weight of the } \\
\text { building }(M N)\end{array}$ & $\begin{array}{c}\text { Equivalent point } \\
\text { load }(k N / m)\end{array}$ & $\begin{array}{c}\text { Angle of tilt in } \\
\text { model } 1\left(^{\circ}\right)\end{array}$ & $\begin{array}{c}\text { Angle of tilt in } \\
\text { model 2 }\left(^{\circ}\right)\end{array}$ & $\begin{array}{c}\text { Angle of tilt in } \\
\text { model 3 }\left(^{\circ}\right)\end{array}$ \\
\hline 1 & 826.15 & 8261.5 & 0.2855 & 0.3942 & 0.8246 \\
2 & 1322.5 & 4963.5 & 0.2781 & 0.3723 & 0.6375 \\
3 & 1787.1 & 4646.0 & 0.2718 & 0.7765 & 0.7350 \\
4 & 2208.25 & 4211.5 & 0.4349 & 0.8789 & 0.7668 \\
5 & 2593.45 & 3852.0 & 0.5366 & 0.7592 & 0.9263 \\
6 & 2969.4 & 3759.5 & 0.5040 & 0.9229 & 1.2616 \\
7 & 3382.0 & 4126.0 & 0.5639 & 0.7372 & 0.9550 \\
8 & 3874.5 & 4925.0 & 0.9086 & 1.4489 & 0.8699 \\
\hline
\end{tabular}

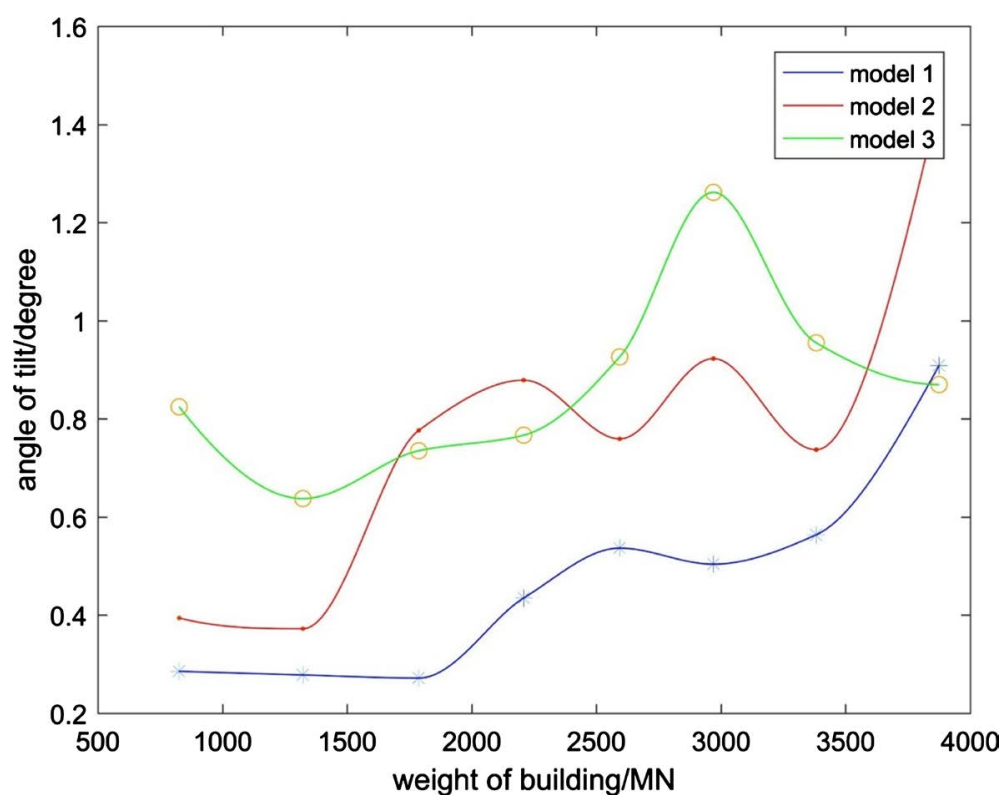

Figure 10. Simulation results of all models.

Pisa tower is a symmetrical circle and the weight of each floor is uniformly distributed, it is reasonable to regard the weight as concentrated load at the centroid. Similar leaning angle could be easily simulated in two-dimension model.

Also the model has its limitations. The first one is that PLAXIS 2D is more suitable in simulating buildings with the same sectional surfaces. However, the tower of Pisa is a hollow cylinder with certain degrees of leaning, meaning that the sections are different; therefore, the results derived cannot be applied to real situations. Soil structure of the 2D model is over-simplified, for the Pisa tower, in reality, first tilted to the north and then to the south during the construction process. In addition, the presence of a gap between the soil and foundation of tower in cohesive soil is ignored, which has a significant effect on the capacity performance [8]. The simulation also lacks precise information, including soil condition and water levels, making it much more constrained. 


\section{Conclusions}

In conclusion, model 3 shows the largest angle of tilt when weight is approximately about $3000 \mathrm{MN}$ in the middle; however, this is not the expected result, for the angle of tilt should increase in positive proportion to the weight. Model 1 and 2 show better simulations, showing the predicted tendency of the tilting angle. As a result, model 3 seems to have some drawbacks in predicting the inclination.

The problems might generate from the distorted form of model 3, since the lower floors of the model are assumed to be perfectly vertical while the upper floors are tilted at 0.6 degrees, different from the form of the tower of Pisa, which has opposite directions of tilting angle in the lower level and the upper one. Thus, model 3 is not very suitable at least in this simulation.

For model 1 and 2, the uprising tendency of the tilting angle corresponds to the initial assumption that the angle of tilt has a positive relationship with the weight.

In the simulation above, the external force comes from the leaning tower of Pisa itself. Since the tower began tilting when the fourth order was constructing, the gravity from the above upper orders can provide the simulation with external force. Moreover, in the models above, certain areas around the building have been circled and meshed with finer elements, showing that the simulation focuses on the direct interaction. The SSI effect is reflected by the simulated tilting angle between the Pisa Tower and the plumb line, displaying the significant role that compressible subsoil has played in the performance of a tall tilting building.

\section{Acknowledgements}

The research team would like to extend our sincere gratitude to our instructor, Professor Ronaldo Borja, for his useful suggestions on our thesis and detailed instructions on modification of our paper. They are deeply grateful for his help in the completion of this work.

Second, thanks should go to the Cathaypath Institute of Science and Zizhu International Education Zone, for providing them a great opportunity to participate in the course of Solid Mechanics and eventually give them the chance in completing this work.

Special thanks also need to be attributed to the research team's tutors, Chen Wei and Liu Zekun, for they have put considerable time and effort into their comments on the draft.

\section{Conflicts of Interest}

The authors declare no conflicts of interest regarding the publication of this paper.

\section{References}

[1] Britannica Online Encyclopedia (2009) Leaning Tower of Pisa (Tower, Pisa, Italy). https://www.britannica.com/topic/Leaning-Tower-of-Pisa 
[2] Duff, M. (2008) Europe | Pisa's Leaning Tower 'Stabilised’. BBC News, 5 May 2009.

[3] Black, C.B. (1898) The Riviera, or the Coast from Marseilles to Leghorn: Including the Interior Towns of Carrara, Lucca, Pisa and Pistoia. A. \& C. Black, London, 148.

[4] Burland, J.B., Jamiolkowski M., Squeglia N. and Viggiani, C. (2013) The Leaning Tower of Pisa. In: Bilotta, E., Flora, A., Lirer, S. and Viggiani, C., Eds., Geotechnics and Heritage, CRC Press, London, 207-227. https://doi.org/10.1201/b14965-11

[5] PLAXIS 8.2 (1998) Finite Element Code for Soil and Rock Analysis, Version 8.2. Brinkgreve, R.B.J. and Vermeer, P.A., Eds. Rotterdam, The Netherlands.

[6] Wolf, J.P. (1985) Dynamic Soil-Structure Interaction. Prentice-Hall, Inc., Englewood Cliffs, New Jersey.

[7] Fiorentino, G., Nuti, C., Squeglia, N., Lavorato, D. and Stacul, S. (2018) One-Dimensional Nonlinear Seismic Response Analysis Using Strength-Controlled Constitutive Models: The Case of the Leaning Tower of Pisa's Subsoil. Geosciences, 8, 228. https://doi.org/10.3390/geosciences8070228

[8] Tuladhar, R., Maki, T. and Mutsuyoshi, H. (2008) Cyclic Behavior of Laterally Loaded Concrete Piles Embedded into Cohesive Soil. Earthquake Engineering \& Structural Dynamics, 37, 43-59. https://doi.org/10.1002/eqe.744 